\title{
Construct validation of an instrument to measure patient satisfaction with pharmacy services in Nigerian hospitals
}

\author{
*Afolabi $\mathrm{MO}^{1}$, Afolabi ERI ${ }^{2}$, Faleye $\mathrm{BA}^{2}$ \\ 1. Department of Clinical Pharmacy \& Pharmacy Administration Unit, Obafemi Awolowo University, IIe \\ Ife, Nigeria \\ 2. Department of Educational Foundations \& Counseling, Obafemi Awolowo University, IIe Ife, Nigeria
}

\begin{abstract}
Background: Patient satisfaction is a multidimensional construct that reflects the type and quality of service provided by healthcare providers, how well it is delivered, and the extent to which the expectations and needs of patients are met. As a performance measure, patient satisfaction has been defined as the personal evaluation of health care services and providers Objective: To develop a patient satisfaction scale, that could be used to assess the quality of pharmacy services provided in Nigerian hospitals and to determine the construct validity of the scale with a view to identifying the factors that may be considered relevant to the target users.

Methods: The questionnaire was a 35-item inventory titled "Patient Satisfaction Survey (PSS)". This study was carried out in three university teaching hospitals located in Southwestern Nigeria. The patient satisfaction survey instrument (PSS) was administered on 506 clinic outpatients who patronised the hospital pharmacies. Participation in the study was voluntary with appropriate informed consent. Ethical approval was obtained for this study from the Medical and Ethics Committee of Obafemi Awolowo University Teaching Hospital Complex (OAUTHC)

Results: Patients with post secondary education were in the majority with a frequency of $224(44.3 \%)$ subjects. This was followed by a frequency of $116(22.9 \%)$ for those with secondary education. Eighty-seven (17.2\%) of those included in the main study had primary education $64(12.7 \%)$ did not receive any formal education. Fifteen (3\%) out of the 506 sampled did not indicate their level of education.

Conclusion: This study developed a scale to measure patient satisfaction with pharmaceutical services in selected Nigerian university teaching hospitals. The final 25 item scale presents significant and stable coefficients of correlation and yielded six derived dimensions of patient satisfaction.

African Health Sciences 2012; (4): 538 - 544 http://dx.doi.org/10.4314/ahs.v12i4.22
\end{abstract}

\section{Introduction}

Patient satisfaction is a multidimensional construct that reflects the type and quality of service provided by healthcare providers, how well it is delivered, and the extent to which the expectations and needs of patients are met. As a performance measure, patient satisfaction has been defined as the personal evaluation of health care services and providers ${ }^{1}$. It serves as a link between services that are provided and patients' needs and desires and allows an assessment that directly reflects the patients' perspective on a service ${ }^{2}$. A review of health care literature showed that data on patient satisfaction can

\section{*Corresponding author:}

Margaret Afolabi

Obafemi Awolowo University

Clinical Pharmacy \& Pharmacy Administration

Nigeria

Email:bunmafol@yahoo.com,

bunmafol@oauife.edu.ng serve as an indicator of service quality and as a predictor of related behavior. It can also be used to assess the performance of health care programmes and of the personnel ${ }^{3}$. Thus, it is expected that patients who are satisfied with health care services are more likely to continue using such services and maintain relationships with specific providers than those who are not ${ }^{4}$.

\section{Measurement of patient satisfaction with Pharmacy services}

Most of the studies that provided a means of measuring patient satisfaction withpharmaceutical services conceptualized satisfaction as a performance evaluation, which ranged from one item to 45 item questionnaire, and focusing on three to nine dimensions of satisfaction. Some authors ${ }^{5}$ included eight dimensions of explanation, consideration, technical competence, financial aspects, accessibility, drug efficacy, non prescription products, and quality

African Health Sciences Vol 12 Issue 4 December 2012 
of the drug product dispensed, while others ${ }^{6}$ reported only four underlying dimensions of patient satisfaction, namely professional communication, physical and emotional comfort, demographic issues and location plus convenience. Other researchers who had developed scales to measure patient satisfaction have come up with various dimensions of satisfaction and these studies portray satisfaction as an experience-based performance evaluation of the services ${ }^{6-8}$.

The objective of this study was to develop a patient satisfaction scale, that could be used to assess the quality of pharmacy services provided in Nigerian hospitals in respect of client perception of specific aspects of service performance, and to determine the construct validity of the scale with a view to identifying the factors that may be considered relevant to the target users. The present study, became necessary in Nigeria because previous studies ${ }^{1,2}$ elsewhere have shown that components of satisfaction relevant to patients in one geographic area or pharmacy setting might be less relevant in another.

An instrument found to be reliable at capturing patients' satisfaction in one geographical location may not be adequate in another circumstance?. This accounts for the need to examine such instruments for their acceptability in terms of reliability and factor dimensions. Reliability is an important criterion in scaling and it deals with the consistency with which a measure could produce similar results when administered more than once (in case of test-retest or equivalent method) or when administered once (in case of internal consistency technique).

\section{Methods}

\section{Design of the questionnaire}

The questionnaire was a 35-item inventory titled "Patient Satisfaction Survey (PSS)". The items were generated from the literature and adaptations from previous scales ${ }^{10}$, and were considered to represent salient aspects of satisfaction. The response format for the items was a Likert scale with five options ranging from "Strongly Agree" to "Strongly Disagree". Each item is a declarative statement with 21 positive and 14 negative items. Examples include: "The pharmacists are courteous to customers" and "The waiting area at the pharmacy is adequate".

The items were subjected to expert (four of them) review for professional judgment on ambiguity, relevance and sentence structure. The experts that carried out the review were researchers in pharmacy practice and evaluators in tests and measurements. The instruments were examined on the relevance of the items to the basic indices of patients' satisfaction and the appropriateness of each item in terms of simplicity/ambiguity, validity, wordings and appropriateness of the options.

\section{Study sites}

This study was carried out in three university teaching hospitals located in Southwestern Nigeria. The teaching hospitals are University College Hospital $(\mathrm{UCH})$, Ibadan; Obafemi Awolowo University Teaching Hospitals Complex, (OAUTHC), Ile-Ife and Ladoke Akintola University Teaching Hospital (LTH), Osogbo with in patient bed capacities of 850600 , and 350 respectively. These teaching hospitals provide specialized services and patients are referred from both primary and secondary healthcare facilities to benefit from highly skilled human resources in these hospitals. The complexity and volume of healthcare activities in these hospitals are reflected in the types of pharmaceutical products and services available in the pharmacies.

\section{Data collection}

The patient satisfaction survey instrument (PSS) was administered on 506 clinic outpatients who patronised the hospital pharmacies. Participation in the study was voluntary with appropriate informed consent. The participants who were unable to complete the PSS by themselves were assisted by trained research assistants.

A total of 506 patients participated in the study and they comprised 258 males and 248 females. Furthermore $21 \%$ of the respondents were students, $38 \%$ were civil servants, and $24.2 \%$ were artisans; the rest were in small scale businesses. Out of the total respondents, $69 \%$ had more than twelve years of formal educationwhile the others had eleven years or less of formal schooling. The participants were a convenience sample of clinic outpatients in attendance at the hospitals.

The initial version of the 35-item PSS was administered on a pilot sample of 30 patients. These consisted of 17 males and 13 females whose ages range from 22 to 71 years. The pilot sample was selected on the basis of convenience and the willingness to participate in the study. The patients were those that came to receive pharmacy services in the hospital different from the main sample. Their responses to the 35 -item scale were used to 
investigate the internal consistency reliability of the initial instrument before the main phase of the data collection. This helped to provide basis for the reduction of the items on the scale to 25 items (from the initial 35 items). The data were collected over three weeks. The result of the analyses conducted from the pilot testing of the instrument is presented in tables 1 and 2.

\section{Data analysis}

Each questionnaire was coded and data were analysed using Statistical Package for Social Sciences (SPSS version 11). The data were subjected to reliability analysis and Principal Components Analysis (PCA). The collected data yielded a Kaiser-MeyerOlkin (KMO) measure of sampling adequacy, value of 0.80 which was an indication that the collected data was suitable for factor analysis. The KMO is one of the statistics used in determining whether a collected set of data is suitable for factor analysis investigations or not suitable. Internal consistency methods of Cronbach coefficient Alpha, Spearman Brown's and Guttmann's coefficients were used to determine the reliability of the scale. The correlation of the scale was carried out both on the initial 35 items and the final scales. Item retention decisions were based on the use of corrected item-total statistics and Cronbach Alpha if-item-deleted approaches ${ }^{13}$. Scree plot for the final 25-item scale was also carried out.

The Scree Plot is a two-dimensional graph that carries factors on its $X$-axis and eigen values on the $Y$-axis ${ }^{15}$. The factor(s) with the greatest 'effect' (depending on rule of determination, usually, values greater-than-one) are considered as the number of factors on the scale. The Scree Plot is generated by employing Principal Component Analysis and this statistic shows the variance accounted for by each underlying factor on the scale. The plot shows the magnitude of eigen values of each of the factors on the scale when plotted on a graph. The factor(s) that fall(s) on the 'steep side' of the graph (before the elbow of the curve) on the left side are the underlying factor(s) on the scale while those appearing after the elbow of the Scree Plot (likened to the base ofa mountain) are simply inconsequential.

Ethical approval was obtained for this study from the Medical and Ethics Committee of Obafemi Awolowo University Teaching Hospitals Complex (OAUTHC).

\section{Results}

Table 1 presents the item statistics of the initial 35 and final 25 items of the questionnaire.

From table 1, low but positive correlations between the items were found, suggesting that the items were measuring different dimensions of patient satisfaction. The deletion of items having low corrected item-total statistics in the initial scale items resulted in improvement in the inter-item correlation of the final 25-item scale. Further, the reliability coefficients of the initial items are presented in table 2

Table 1: Summary item statistics of initial and final scale items

\begin{tabular}{|c|c|c|c|c|c|c|c|c|c|c|}
\hline & \multicolumn{5}{|c|}{ Initial scale } & \multicolumn{5}{|c|}{ Final scale } \\
\hline & Mean & SD & Min. & Max. & Range & Mean & SD & Min. & Max. & Range \\
\hline Item Mean & 2.66 & 1.64 & 1.02 & 4.02 & 3.00 & 2.79 & 1.09 & 1.88 & 3.62 & 1.74 \\
\hline $\begin{array}{l}\text { Inter-Item } \\
\text { correlation }\end{array}$ & 0.47 & 0.05 & 0.42 & 0.67 & 0.25 & 0.52 & 0.03 & 0.43 & 0.75 & 0.32 \\
\hline
\end{tabular}

Table 2: Coefficients of reliability of the patient satisfaction survey

\begin{tabular}{lll}
\hline Reliability & $\mathbf{N}=\mathbf{3 5 *}$ & $\mathbf{N}=\mathbf{2 5 *}$ \\
\hline Cronbach Alpha & 0.67 & 0.71 \\
$\begin{array}{l}\text { Spearman - Brown } \\
\text { (unequals lengths) }\end{array}$ & 0.75 & 0.78 \\
Guttman split - half & 0.75 & 079 \\
\hline
\end{tabular}

$* \mathrm{p}<0.05$ - results are significant 
Table 2 shows that consistently greater reliability coefficients were obtained on the 25 -item scale than on the initial 35 items, each being significant at $\mathrm{p}$ $<0.05$. Initial Factor Analysis using Eigen Value Greater than One suggested the presence of seven factors in the scale but Principal Component Analysis (PCA) with varimax rotation revealed six factors on which the 25-item scale loaded, accounting for $51.3 \%$ of the total scale variance. This suggests that the factors on the scale were reducible to six factor components reflecting key dimensions of pharmacy services perceived as important by patients. A Scree plot (figure. 1) for the PSS further confirms this factor composition.

Scree Plot

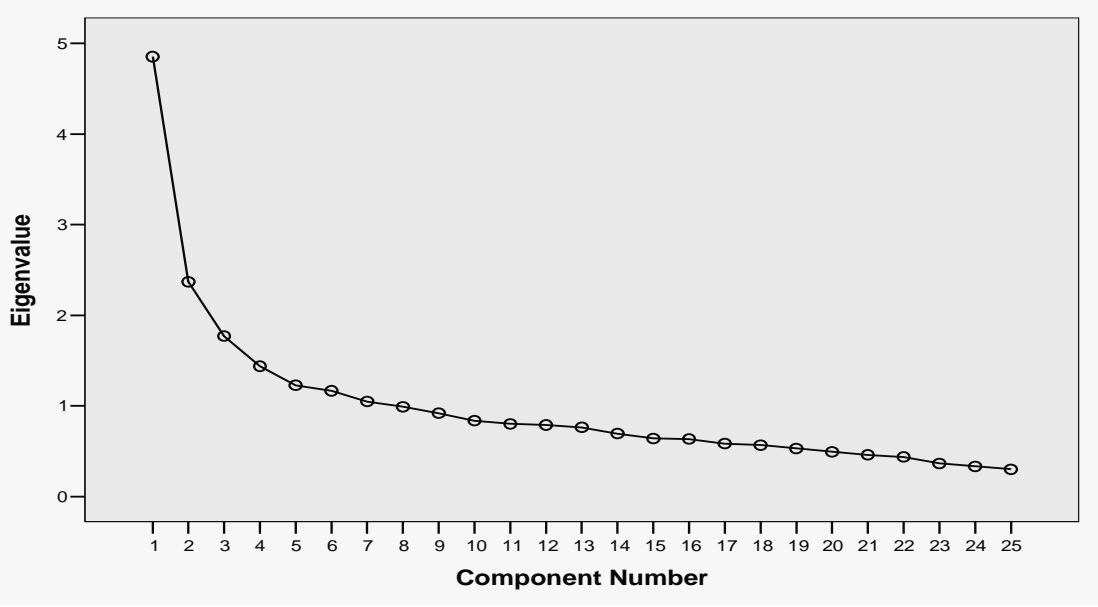

Figure 1: Screen plot for the final PSS scale

The six factors (with eigenvalue greater than one) are: (i) attitude of pharmacy personnel, (ii) accessibility and convenience of pharmacy location, (iii) quality and cost of drugs, (iv) conducive physical environment, (v) availability of prescribed drugs, and (vi) timeliness of service delivery.

In order to further investigate the quality of the result obtained, the influence of sample-related factors such as educational background and sex were examined. The results showed that patient satisfaction reduced with increase in level of education. The mean scores on patient satisfaction in relation to educational level are presented in table 3.

\section{Table 3: Scale Item Means in respect of} Educational Levels

\begin{tabular}{lcc}
\hline Level of education & $\mathbf{n}$ & $\mathbf{0}$ \\
\hline Without any formal education & 64 & 12.7 \\
With primary education & 87 & 17.2 \\
With secondary education & 116 & 22.9 \\
With post secondary education & 224 & 44.3 \\
No response & 15 & 2.9 \\
Total & 506 & 100 \\
\hline
\end{tabular}

Patients with post secondary education were in the majority with a frequency of 224 (44.3\%) subjects. This was followed by a frequency of $116(22.9 \%)$ for those with secondary education. Eighty-seven $(17.2 \%)$ of those included in the main study had primary education $64(12.7 \%)$ did not receive any formal education. Fifteen $(3 \%)$ out of the 506 sampled did not indicate their level of education. The results of ANOVA on the influence of educational level on patients' responses to scale items are presented in table 4 .

From table 4, the F-ratio of 22.9 was significant $(\mathrm{p}<0.05)$, thus suggesting that level of education had an influence on patients satisfaction with pharmacy services. When subjected to Scheffe's Multiple Comparison, it was discovered that the highest group difference exist between those without formal education and those with formal education. This is presented in table 5 : 
Table 4: Influence of level of education on Scale item responses

\begin{tabular}{lllcll}
\hline Sum of Squares & Df & \multicolumn{2}{l}{ Mean Square } & $\mathbf{F}_{1 .}$ & P \\
\hline Between groups & 6860.15 & 3 & 2286.72 & 22.90 & $<0.05$ \\
Within groups & 48627.82 & 487 & 99.85 & & \\
Total & 55487.97 & 490 & & & \\
\hline
\end{tabular}

Table 5: Multiple comparisons of the differences introduced by level of education on item response

\begin{tabular}{llr}
\hline Patients' Level of Education & Patients' Level of Education & $\begin{array}{r}\text { Mean } \\
\text { difference }\end{array}$ \\
\hline Without any formal education & With primary level of education & 0.99 \\
& With secondary level of education & 2.36 \\
With primary level of education & With post secondary level of education & $8.72^{*}$ \\
& Without any formal education & -0.99 \\
& With secondary level of education & 1.37 \\
With secondary level of education & With post secondary level of education & $7.72^{*}$ \\
& Without any formal education & -2.36 \\
& With primary level of education & -1.37 \\
With post secondary level of education & With post secondary level of education & $6.36^{*}$ \\
& Without any formal education & $-8.72^{*}$ \\
& With primary level of education & $-7.72^{*}$ \\
& With secondary level of education & $-6.36^{*}$ \\
\hline
\end{tabular}

Note: ${ }^{*} \mathrm{p}<0.05$, result significant

Furthermore, the influence of sex on patients' responses to the scale items was examined using ttest. The results of t-test analysis conducted showed that sex had significant influence on the rresponses of patients to scale items on satisfaction with pharmaceutical services $(\mathrm{t}[\mathrm{df}: 504]=2.63)$. In particular, female patients expressed greater satisfaction with pharmaceutical services (mean $=$ $66.25)$ than their male counterparts (mean $=63.78)$. In particular, female patients expressed greater satisfaction (mean $=66.25$ ) with the services than their male counterparts (Mean $=63.78)$. The age of respondents ranged from 21 years to 72 years (mean age $=46, \mathrm{SD}=18.47$ ) but this was not examines as a sample related factor in this study.

Many of the 25 items on the scale loaded on more than one item. They are so retained because the instrument was still new to the environment. With further analyses, some of the items could be revisited for rewording or outright removal from the scale (given that the Cronbach's alpha will be more than 0.70). The Cronbach's alpha of the items that loaded on each of the six factors is presented in table 5 .

Table 6: Rotated Factor Loadings for the 25 Items on the Scale.

\begin{tabular}{|c|c|c|c|c|c|}
\hline \multirow[t]{2}{*}{ No } & \multirow[t]{2}{*}{ Item } & \multicolumn{4}{|c|}{ Factor Loadings } \\
\hline & & 1 & 2 & 3 & 4 \\
\hline 1 & The pharmacy is easy to access in the hospital & 0.40 & - & - & \\
\hline 2 & The general environment of the pharmacy is satisfactory & 0.46 & - & - & \\
\hline 3 & The pharmacy space is adequate & 0.39 & - & - & \\
\hline 4 & The pharmacy does not need to open for 24 hours daily & - & - & - & 0.34 \\
\hline 5 & The waiting area of the pharmacy is inadequate & 0.30 & - & - & - \\
\hline 6 & Waiting time at the pharmacy is too long & 0.55 & - & - & - \\
\hline 7 & Each time I visit the pharmacy my drug needs are met & - & - & - & 0.34 \\
\hline 8 & The price of drugs at the pharmacy is lower than what obtains outside & - & - & - & 0.39 \\
\hline 9 & The pharmacists are courteous to customers & 0.70 & - & - & - \\
\hline 10 & The direction for drug use on bottles are clear and readable & 0.47 & - & 0.38 & $8-$ \\
\hline 11 & Pharmacists at the pharmacy are not easily app-roachable & 0.32 & 0.31 & - & - \\
\hline
\end{tabular}




\begin{tabular}{|c|c|c|c|c|c|c|}
\hline \multirow[t]{2}{*}{ No } & \multirow[t]{2}{*}{ Item } & \multicolumn{5}{|c|}{ Factor Loadings } \\
\hline & & 1 & 2 & & & 4 \\
\hline$\overline{12}$ & The Pharmacy appears to be stocked with the type of drugs most people need & - & - & & 0.53 & \\
\hline 13 & The pharmacists on duty usually counsel patients on the use of drugs being purchased & 0.51 & - & 0.4 & & \\
\hline 14 & The cashier is courteous to customers & 0.59 & - & - & - & \\
\hline 15 & $\begin{array}{l}\text { It takes an unnecessarily long time for the prescriptions submitted at the pharmacy } \\
\text { to be dispensed }\end{array}$ & 0.46 & 0.32 & - & - & \\
\hline 16 & I am satisfied with the services at the pharmacy & 0.73 & - & - & - & \\
\hline 17 & The pharmacy should be more centrally placed within the hospital & - & & & & \\
\hline 0.57 & 0.41 & - & & & & \\
\hline 18 & The pharmacists on duty do not seem to appreciate the health status of patients & 0.45 & 0.37 & - & - & \\
\hline 19 & Generally, the pharmacy staff relate well to customers & 0.74 & - & - & & \\
\hline 20 & The Pharmacists usually provide additional advice or information & 0.58 & - & 0.4 & & \\
\hline 21 & The waiting time to know the cost of drugs is too long & 0.42 & 0.37 & - & & \\
\hline 0.35 & & & & & & \\
\hline 22 & The waiting area should be enclosed for patient convenienceand privacy & - & 0.79 & - & & \\
\hline 23 & The hospital should provide adequate direc-tions to locate thepharmacy & - & 0.68 & - & & \\
\hline 24 & I think the staff at the pharmacy is inad-equate & - & - & - & 0.43 & \\
\hline 25 & Drugs sold at the pharmacy can be trusted for their genuinenessor quality & 0.42 & - & - & & \\
\hline
\end{tabular}

*Factors with significant loadings:

$1=$ attitude of pharmacy personnel

$2=$ accessibility of pharmacy location

$3=$ quality and cost of drugs

$4=$ conducive physical environment

Item loadings across the six factors are contained in table 6 . The coefficients of item loadings on the first factor (attitude of pharmacy personnel) are highest of all the loadings for the six factors on the scale.

\section{Discussion}

The instrument used in this study was based on the conceptualisation of patient satisfaction as a multidimensional construct incorporating relevant items on both the performance evaluation and consumer expectations. The six derived factors of patient satisfaction in the study are similar, in some ways, to the items identified in previous studies ${ }^{6,8,12}$. It is interesting to note that, accessibility, convenience and professional competence appear to be factors that are common in these studies. Although a recent update $^{2}$ of a patient satisfaction instrument ${ }^{12}$ identified only two dimensions of pharmaceutical care-friendly explanation and managing therapy the component items of the study seemed to compare mostly with items relating to professional competence. Closely related to the issue of professional competence is the attitude of pharmacy personnel while rendering their services to patients. Most often, people's culture tend to becloud their sense of judgment of how well individuals or organisations render their services. This may explain patient preference of a more distant pharmacy for their purchases rather than patronise a near location. However, accessibility and convenience contribute largely to patient satisfaction with pharmacy services as in a previous study ${ }^{4}$.

Findings of the study showed that the emerging factors of quality, cost and availability of medicines along with the physical environment might be linked to the socioeconomic conditions in Nigeria. Similarly, timeliness of service has to do with patient waiting time at the pharmacies and for many people who do not patronise public hospitals, excessive waiting time at various units of the hospital is often cited as the major reason for their preference of private health institutions. A review of the workflow in public hospital pharmacies might identify delay points that should be addressed to reduce patient waiting time. The reliability coefficients obtained for the instrument using different approaches are comparable and statistically significant. The inter-item correlations also tend to suggest that the items are measuring the same concept that is, patient satisfaction; and are indicative of construct validity ${ }^{3,13}$. 
A major strength of this study is the consultation of patients before the design of the PSS. Their submission on the dimensions of patients' satisfaction contributed richly to the development of the instrument. Furthermore, the use of Nigerian sample for the validation of the PSS is also a strength? ${ }^{9}$ The use of samples resident in an environment is an advantage that takes care of cultural and environmental factors that may lead to differences in an instrument's ability to validly measure an object of interest.

\section{Conclusion}

This study developed a scale to measure patient satisfaction with pharmaceutical services in selected Nigerian university teaching hospitals. The final 25 item scale presents significant and stable coefficients of correlation and yielded six derived dimensions of patient satisfaction. These factors appeared to capture the important concerns of Nigerian patients who came to obtain prescribed medicines in the hospital pharmacies. The identified underlying factors could be used to improve pharmacy services in the hospitals and also in the training of pharmacy students in pharmaceutical care. The psychometric properties obtained suggest a need for further refinement of the items. It is also likely that the heterogeneity of the respondents might have contributed to the low item means.

\section{References}

1. Schommer JC, Kucukaslan SN. Measuring patient satisfaction with pharmaceutical services. Am J. Health. Syst Pharm 1997; 54: 2721-32

2. Larson, LN, Rovers JP and Mackeigan LD. Patient satisfaction with pharmaceutical care: Update of a validated instrument. J. AmerPharm Assoc. 2002; 42(1): 44-50.

3. Ware, J.E; Wright WR, Snyder MK and Chu, GC. Consumer perceptions of health care services: Implications for academic medicine. $J$ Med Educ 1975; 50: 839-48.
4. Oparah AC, and Kikanme LC. Consumer satisfaction with community pharmacies in Warri Nigeria. Res Social Adm Pharm.2006; 2(4): 499511

5. MacKeigan LD,Larson LN.Development and validation of an instrument to measure patient satisfaction with pharmacy services. Med care 1989;27: $522-36$.

6. Lang JR, Fullerton SD. The components of satisfaction with outpatient pharmacy services. Health Mark Q. 1992; 10: 143-54.

7. Briesacher B, Corey R. Patient satisfaction with pharmaceutical services at independent and chain pharmacies. Am J Health. Syst pharm. 1997; 54:531-6

8. Lipowski EE. Patient satisfaction and perceived quality of pharmaceutical care. Presented at the Annual Meeting of the American Association of Colleges of Pharmacy. Philadelphia, PA; 1995 Jul 11.

9. Faleye, BA. Reliability and Factor Analyses of a Teacher Efficacy Scale for Nigerian Secondary Schools. Electronic Journal of Research in Educational Psychology, University of Almeria, Spain. Available a t: ht t p: / / w w w. investigacionpsicopedagogica.org/revista/english/

10. Garrat MG, Danielsen, K and Hunskaar S. Patient Satisfaction Questionnaires for Primary Care Out-of-Hours Systematic Review. The British Journal of General Practice. 2007; 57(542): $741-747$.

11. Newsom, SEM. A Quick Primer on Exploratory Factor Analysis. Retrieved on 29/ 03/2009 from: www.upa.pdx.edu/IOA/ Newsom/semcllass/ho_fa.doc

12. Larson LN, MacKeigan LD. Further validation of an instrument to measure patient satisfaction with pharmacy services. J. Pharm Mark. Manag. 1994; 8 (1): 125-39.

13. Thompson B, Daniel LG. Factor Analytic Evidence for the Construct Validity of Scores:A Historical Overview and some Guidelines. Educational and Psychological Measurement. 1996;56: 197-208. 